\title{
Effect of Public Distribution System Workers in Influencing the Women Street Vendors to Use Banks - Enabling Financial Inclusion
}

\author{
Praveen Paul Jeyapaul $1^{*}$ and Silambarasan Manimaran ${ }^{2}$ \\ ${ }^{1}$ Doctor of Philosophy (PhD) in Business Administration, Professor, Mepco School of Management Studies, Sivakasi, Tamil Nadu, India \\ ${ }^{2}$ Assistant Professor, Mepco School of Management Studies, Sivakasi, Tamil Nadu, India
}

*Corresponding author: jpraveen@mepcoeng.ac.in (ORCID ID: 0000-0002-3849-4291)

Received: 13-03-2021

Revised: 25-05-2021

Accepted: 05-06-2021

\begin{abstract}
Women street vendors especially face tremendous challenges in terms of their financial security. Using banks for their financial transaction will give them respite from private money lenders, thereby leading to these "women's' financial inclusion in the society. To convince these women street vendors to increase their usage of banks, it is proposed to garner the help of workers from the public distribution system (PDS). It is hypothesized that these PDS workers will act as influencers in convincing the women street vendors (SVs)to use the banks in a better manner. Two sets of questionnaires were developed. Initially, one was administered to get their bank usage pattern and PDS workers were then requested to educate the Women SVs on the benefits of banks. After six months, the second questionnaire was administered to find any significant change in behavior with the same set of women street vendors. The effect of age and education level of the women SVs in accepting the advice of PDS workers to use banks is investigated using a Multivariate generalized linear model (MGLM). The results of the MGLM suggest that education level of the SVs has an evident and contingent influence on their acceptance of PDS worker's advice, while age makes no significant difference. To compare whether the mean of the dependent variable (knowledge about bank) is the same or changed (change in knowledge about bank) before and after the PDS workers have educated the women SVs, paired-samples T test is used. Based on the results, it is concluded that the PDS workers make a difference in educating the Women SVs on the benefits and purpose of using banks. In order to find out exactly where the difference occurs between the groups a post hoc test is carried out. The outcome of the post-hoc test suggests that the impact of PDS workers is higher with the Women SVs whose education levels are lower. However, there is no improvement on the opinion in the women SVs whose education level is higher. It is suggested that policymakers use PDS workers to target women SVs with lower education levels to educate them on the benefits of using banks for financial transactions instead of relying on private money lenders.
\end{abstract}

\section{HIGHLIGHTS}

(0 Financial inclusion of women street vendors (SVs)

(0 Educating women SVs on the benefits of using banks through PDS workers

( Change in perception among women SVs after PDS workers educating them

(- Education level among women SVs have significant influence in accepting PDS 'workers' suggestions

( Age has no impact in accepting PDS 'workers' suggestions

Keywords: Women street vendors, public distribution system workers, bank usage, financial inclusion, education level

How to cite this article: Jeyapaul, P.P. and Manimaran, S. (2021). Effect of Public Distribution System Workers in Influencing the Women Street Vendors to Use Banks - Enabling Financial Inclusion. Int. J. Soc. Sci., 10(02): 89-97.

Source of Support: None; Conflict of Interest: None 
Street vendors (SVs) eke out a living by selling toys, flowers, food etc., on the streets daily. Rain or shine, they need to be on the job to ensure their livelihood. SVs contribute significantly to the informal economy, and the informal economy contributes to the GDP of any economy. Women SVs across the globe do not enjoy the benefits of the male SVs. They are physically abused, undergo domestic violence, and generally work overtime to make up their living (Kaur 2020) (Abebe, 2017). The primary reason for such ill-treatment is that they are not financially included and have limited legal protection from labor rights (Sekhani et al. 2019). Especially in India, the government has taken many steps in bringing the SVs into the mainstream by financially including them. One such attempt in India is Pradhan Mantri Jan Dhan Yojana (PMJDY), whose sole motive is to provide affordable access to financial services like bank loans, bank accounts, insurance, pension, etc the citizens of the country (PMJDY, 2014). Despite such efforts by the government and the Reserve Bank of India, the final benefits of the financial services are still beyond their reach. People in rural areas still do not have access to banking services. Lacks of financial literacy, and too much dependence on moneylenders for immediate loans are considered critical issues (Singh and Gupta, 2020). The status of SVs, particularly women, is in a pathetic situation.

Women are empowered when they have access to financial and economic resources. Financial inclusion (FI) helps women being empowered by having access to loans, credit, and other facilities provided by the government. Financially empowered, they come into the mainstream formal economy. Moreover, FI helps to remove poverty by allowing women to build assets safely and save money (Gupta, 2021). Study in Bangladesh also portrays that street vending business provides a sustainable livelihood by alleviating poverty (Sarker et al. 2019). Households led by women have limited access to formal finance compared to lead by men. Improvement in household education makes it likely to access formal sources like banks for borrowings than going for informal sources (Ghosh and Vinod, What Constrains Financial Inclusion for Women? Evidence from Indian Microdata, 2017). The informal sector contributes significantly to the development of any economy. Street Vending business has a significant impact on the informal 'sector's dominance. It is one of the readily available opportunities of employment open to women who need to make a living. Low-cost investment, lean barriers, lower skill requirements make street vending business in a country like India high lucrative and suitable for women (Cohen et al. 2000) (Kaur, 2020). According to the report from the National 'Women's Commission highlights that in India, 94\% of women are employed in the unorganized sector (Kaur 2020). Nearly 20 million people are involved in the street vending business in India, and one-third of them are women (Kaur et al. 2020).

Contrary to that in Sub-Saharan Africa, Indonesia, Thailand, Vietnam, and China, women enjoy a significant share of informal employment through street vending. There is a proportionately higher number of them compared to men in most cities (Mungai et al. 2019) (Sekhani et al. 2019) (El-Azzazy, 2019). In Columbia, due to child care reasons, preference for women towards street vending is comparatively lesser (Bernal-Torres et al. 2020). Nearly 30\% of SVs in New Delhi, 'India's capital, are women. Street vending jobs enhance women's confidence and providem a clear upper hand in family decision-making (Thakur et al. 2017). Though street vending is lucrative, it is the economic inability that compels women to go without option. Unlike men, who use pushcarts, baskets, two-wheelers as street vending modes, women mostly depend on baskets on pavements and streets. Moreover, the earnings women make are comparatively lesser than their male counterparts (Chakraborty, 2018). National Association of Street Vendors of India (NASVI) is the body created to uplift the quality of life of SVs in India (Swamy and Singh, 2018)

Limited access to formal, regulated market space, obliged to operate outside the legal framework, limited legal protection from labor rights, unregistered and unrecognized status by the government, and poor working conditions are some characteristics of street vending business making it vulnerable to the vendors. The above characteristics also make them establish as 'invisible 'entrepreneurs' (Sekhani et al. 2019). Lack of 
sanitation access, physical abuse, theft, domestic and public violence, refusing to pay, working overtime, and damaging goods add agony to women involved in street vending (Kaur2020), (Abebe, 2017). In Ethiopia, SVs who are young girls and aged women are harassed and fined by policemen for not having permits. They are also abused by street gangs by snatching their money and stealing goods (Lemessa et al. 2021). To make things worse, life after the covid19 pandemic for women SVs have become pathetic. More than $97 \%$ of women SVs in New Delhi, India are adversely affected by the lockdown (Kaur et al. 2020). Being in harmony with the male counterpart in the family acts as an ailment for the women's abuses (Ismail and Umar, 2018). In Hanoi, Vietnam, the government banned street vending business as it affects the image of the city among tourists (Truong 2018). Women Food Vendors in Harare, Zimbabwe, find that lack of adequate financial resources is the main reason which hinders their business progress (Thabani, 2017). A study among women fish vendors in Egypt found that they face harassment and violence, have the burden of performing paid and unpaid work, lack access to credit, and these burdens limit their continuity towards business (El-Azzazy, 2019). Women SVs lose most of their savings to private load sharks as interest for their loan. Loans from formal financial sources are still beyond their reach due to the complicated documentation process(Sen and Gupta, 2017). Study results from Hyderabad reveal that majority of the women street vendors are illiterate, and most of them belong to the scheduled castes (Begari, 2017). Despite all these challenges women SVs are still optimistic and are the major source of bread winner for their family(Sen and Gupta, 2017). Recognizing the opportunity, taking initiatives and change creation are the proactive factors influencing the growth of women street vending, leading to profitability and business stability (Mungai et al. 2019).

Though the concept of Public Distribution System (PDS) was established in the 1960s itself in India, only in the year 1997 Targeted Public distribution system (PDS) was launched by the government with a chain of shops with the prime motive of distributing basic food and non-food commodities to the poor people at a lower price. It comes under the ministry of consumer affairs, food and public distribution (TPDS, 1997) (The Economic Times, 2020). The PDS workers are regularly in contact with the local people of their particular area as they are responsible for distributing food supplies. The PDS in India is a very successful program and has a strong chain even in the deeper roots of the villages. Indian citizens with ration card can avail this facility as per the schedule given by the government.

\section{Methodology}

This research aims to find if the PDS workers will act as influencers to persuade women SVs to adopt banks for their financial transactions, thus enabling financial inclusion. In order to find this, a pre and post-test was conducted before and after the intervention of PDS workers with structured questionnaires. Initially, 110 women SVs were chosen from seven taluks of Virudhunagar district, and the first questionnaire was administered. The first questionnaire sought information regarding their daily money requirement for doing business, daily earnings, and using banks apart from other relevant items. Then the PDS workers in the respective geographical area were requested to educate and persuade these women SVs regarding the advantages of using the bank as their primary source of money transaction. Six months after this education given by the PDS workers, the second questionnaire was administered to the same set of women SVs to measure the change in their opinion towards using banks. These SVs were segregated into multiple groups based on their age and multiple groups based on their education.

Table 1: Distribution of women SVs among the taluks of Virudhunagar district

\begin{tabular}{ll}
\hline Taluk & Respondents \\
\hline Kariyapatti & 4 \\
Rajapalayam & 30 \\
Sattur & 5 \\
Sivakasi & 19 \\
Srivilliputtur & 37 \\
Thiruchuli & 2 \\
Virudhunagar & 13 \\
\hline Total & $\mathbf{1 1 0}$ \\
\hline
\end{tabular}


First, to understand if there is any impact from age and education of the women SVs in accepting the advice of PDS workers, a Multivariate generalized linear model (MGLM) is used. Multivariate (generalized linear model) GLM is the extended form of GLM, and it deals with more than one dependent variable and one or more independent variables. The GLMMultivariate procedure provides regression analysis and analysis of variance for multiple dependent variables by one or more factor variables or covariates. The factor variables divide the population into groups. Using this general linear model procedure, one can test null hypotheses about the effects of factor variables on the means of various groupings of a joint distribution of dependent variables. Anyone can investigate interactions between factors as well as the effects of individual factors. In addition, the effects of covariates and covariate interactions with factors can be included. For regression analysis, the independent (predictor) variables are specified as covariates. Suppose more than one dependent variable is specified. In that case, the multivariate analysis of variance using Pillai's trace, Wilks' lambda, Hotelling's trace, and Roy's largest root criterion with approximate F statistic are provided and the univariate analysis of variance for each dependent variable. In addition to testing hypotheses, GLM Multivariate produces estimates of parameters.

To find if there is a change in opinion on using banks before and after the PDS 'workers' influence among women SVs, paired sample t-test is used. The Paired Samples t-test compares the means of two measurements taken from the same individual from the measurements taken at two different times. 'Post hoc tests are used to uncover specific differences between three or more group means. To find where the differences lie between the individual groups, Fisher's Least Significant Difference (LSD) post hoc test is carried out using IMB® SPSS Statistics ${ }^{\circledR}$.

\section{RESULTS AND DISCUSSION}

The research wanted to explore the impact of PDS workers in educating the women SVs in using the banks regularly to improving the SVs FI. It was hypothesized that PDS workers would act as influencers in urging the SVs to take up the regular banking services to improve their FI and thus their lifestyle. In order to test the hypothesis, separate questionnaires were prepared with similar questions and administered to the SVs were; the first questionnaire asked if they considered PDS workers as their influencers and will listen to the advice of PDS workers on financial matters and issues leading to SVs regular usage of banking services. The second questionnaire was administered to the same set of SVs after approximately six months. In the second questionnaire, it was asked if they have started using banks regularly based on the advice from PDS workers.

A preliminary investigation was carried out in finding the effect of age and education level of the women SVs in accepting the advice of PDS workers to use banks leading to FI. For this Multivariate generalized linear model (MGLM) is used. Here the influence of age and education level of women SVs on their opinion change because of the PDS worker influence is tested. Further paired samples, T-test is used to compare whether the mean of the dependent variable (knowledge about bank) is the same or changed (change in knowledge about bank)before and after the PDS workers have spoken with the women SVs.

The results of the MGLM are presented in Table 2. It is quite clear from the results that the education level of the SVs has a clear and contingent influence on their acceptance of PDS worker's advices, while age makes no significant difference. This is evident from the fact that the results of $p$ value at $p \leq .001$, shown in Table 2. Here, for the influence of "education', the $p$ values are less than .001 for all the indices (Pillai's Trace, Wilks' Lambda, Hotelling's Trace, and Roy's Largest Root), considered and thus the null hypothesis that there is no significant effect from the education of women SVs is on their predisposition to listen to PDS workers is rejected, and it is accepted that education has a significant influence on women SVs to listen to PDS workers to use banks regularly to enable FI. Similarly, looking into the $\mathrm{p}$ values exhibited for 'age' is quite clear that at $\mathrm{p}$ $\leq .05$, the $\mathrm{p}$-value for all the indices is greater than .05 , and thus the null hypothesis that 'age' has no significant impact on the women SVs to listen to PDS workers is accepted and concluded thus. 
Effect of Public Distribution System Workers in Influencing the Women Street Vendors to Use Banks...

Table 2: Multivariate GLM for age and education of women SVs

\begin{tabular}{|c|c|c|c|c|c|}
\hline Effect & & Value & $\mathbf{F}$ & Hypothesis df & Sig. \\
\hline \multirow{3}{*}{ Education } & Pillai's Trace & .622 & 7.133 & 10.000 & .000 \\
\hline & Wilks' Lambda & .435 & 8.065 & 10.000 & .000 \\
\hline & Roy's Largest Root & 1.046 & 16.534 & 5.000 & .000 \\
\hline \multirow{2}{*}{ Age } & Pillai's Trace & .071 & .482 & 12.000 & .923 \\
\hline & Roy's Largest Root & .047 & .620 & 6.000 & .714 \\
\hline \multirow{3}{*}{ Education * Age } & Pillai's Trace & .155 & .442 & 30.000 & .995 \\
\hline & Wilks' Lambda & .849 & .442 & 30.000 & .995 \\
\hline & Hotelling's Trace & .172 & .442 & 30.000 & .995 \\
\hline
\end{tabular}

Further, observing the different indices of Multivariate generalized linear model, it can be concluded that the factor' 'education' is important in differentiating women SVs in accepting the PDS 'workers' advice in using banks for FI. Looking at the indices individually, the larger the Pillai's trace, the more the given effect contributing to the model. Here, the Pillai's trace is 0.622 , which is considered quite significant. Similarly, the larger the Hotelling's trace, the more the given effect contributing to the model. Pillai's trace is always smaller than Hotelling's trace. Here the Hotelling's trace is also quite large. The next index considered is 'Wilks' lambda, whose value ranges from 0 to 1 . Lower the Wilks' lambda, the more the given effect contributing to the model. In this case, the Wilks' lambda may be considered to be quite low, thus making the model quite robust. Finally, Roy's largest root (RLR) is computed. The larger the root, the more the effect contributing to the model. Here again, the RLR value is quite big. Further the F values in the model also indicated that the model is robust. Considering all the indices discussed, it may be safely concluded that "'education' level of the women SVs has a significant and contingent effect on the predisposition of women SVs in accepting the advice of PDS workers leading to the SVs FI.

In the next part of the analysis, it is endeavored to determine whether the mean of a dependent variable (knowledge about bank) has changed or remains the same after the PDS workers enlightened the women SVs on the benefit of using the banks, which will lead to the women SVs FI. As mentioned already, the paired-samples $t$ - test compares the means of two measurements taken from the same individual from the measurements taken at two different times. Observing the mean values in Table 3 for pre and post-change in knowledge about bank and its purpose after the intervention by PDS workers, the values suggest that there is an increase in the opinion (from $\bar{x}=3.164\left(\int=0.89\right)$ to $\bar{x}=4.591$ ( $\int$ $=0.49$ ) among women SVs about their knowledge about bank and its purpose. The change is approximately 1.5 in a scale of 5 , with a low $\int$. This may be considered a significant change since five-point scales was used for the measurement of this factor/opinion. Thus it may be tentatively concluded that there is a significant impact from the advice of PDS workers on women SVs to use banks. Hence it may also be concluded that women SVs do take the opinion of PDS workers seriously.

Table 3: Paired Samples T Test Statistics

\begin{tabular}{lllll}
\hline Factors & Mean & $\mathbf{N}$ & $\begin{array}{l}\text { Std. } \\
\text { Deviation }(~\end{array}$ & $\begin{array}{l}\text { Std. } \\
\text { Error } \\
\text { Mean }\end{array}$ \\
\hline $\begin{array}{l}\text { PRE knowledge about } \\
\text { bank and its purpose }\end{array}$ & 3.164 & 110 & .8937 & .0852 \\
$\begin{array}{l}\text { POST knowledge about } \\
\text { bank and its purpose }\end{array}$ & 4.591 & 110 & .4939 & .0471 \\
\hline
\end{tabular}


In order to check if the change in the women SVs disposition on their knowledge about banks and its purpose after the PDS workers have spoken with them (PRE vs POST) is statistically significant, the values shown in paired samples test (Table 4) is investigated. The null hypothesis proposed here is that there is no significant difference in the PRE and POST change in knowledge about the bank and its purpose. As indicated in the preceding discussion, the mean value in Table 4 indicates that there is a change to the magnitude of 1.4273 ( $\bar{x}$ of PRE knowledge about bank and its purpose (3.164) $-\bar{x}$ of POST knowledge about bank and its purpose (4.591)). The negative values of mean and $t$ is because of the computation of difference with the PRE values first and POST values next. The p-value is .000 at $\mathrm{p} \leq .001$, defeating the null hypothesis that there is no significant change between the PRE and POST change in knowledge about the bank and its purpose. Thus now it can be safely concluded that the PDS workers make a difference in educating the Women SVs on the benefits and purpose of using banks, thus leading to the FI of Women SVs. Further, it may also be stated that the POST effect is stronger by considering the $t$ value. Here, the $t$ value is quite high, indicating a strong influence from the PDS workers on women SVs.
In order to find out exactly where the difference occurs between the groups a post hoc test is carried out, and the results of the post hoc tests are presented in Tables 5 and 6. From Table 4, it's clear that there is a significant change in the opinion of the Women SVs on their knowledge about bank and its purpose after the PDS workers counseled them. However, looking for the exact incidence of this change, we examine the $p$ values in Table 5. While considering the $p$ values of the test of between-subjects effects, it can be seen that under the source Education, the null hypothesis of no effect of education on PRE PDS workers influence on knowledge about bank and its purpose among women SVs is accepted. However, the p values under POST the PDS workers influence on knowledge about bank and its purpose among women SVs, indicate that the alternate hypothesis that there is a significant impact from 'education' on the women SVs knowledge about bank and its purpose is accepted and concluded that education influences women SVs acceptance of PDS workers counseling. Further, the $p$ values for PRE and POST under 'age' indicates that there is no significant impact either on PRE or POST - PDS workers' influence on women SVs regarding their age. In other words, age has no significant impact on the women SVs acceptance

Table 4: Paired Samples Test

\begin{tabular}{llllll}
\hline & \multicolumn{4}{c}{ Paired Differences } \\
\cline { 2 - 5 } Factors & Mean & $\begin{array}{l}\text { Std. } \\
\text { Deviation }\end{array}$ & $\begin{array}{l}\text { Std. Error } \\
\text { Mean }\end{array}$ & $\begin{array}{l}\text { 95\% Confidence Interval of the } \\
\text { Difference }\end{array}$ & Sig. \\
\cline { 5 - 6 } $\begin{array}{l}\text { PRE knowledge about bank and its } \\
\text { purpose - POST knowledge about bank } \\
\text { and its purpose }\end{array}$ & -1.4273 & 1.0875 & .1037 & -1.6328 & -1.2218 \\
\hline
\end{tabular}

Table 5: Tests of Between-Subjects Effects

\begin{tabular}{|c|c|c|c|c|c|c|}
\hline Source & Dependent Variable & $\begin{array}{l}\text { Type III Sum of } \\
\text { Squares }\end{array}$ & DF & $\begin{array}{l}\text { Mean } \\
\text { Square }\end{array}$ & $\mathbf{F}$ & Sig. \\
\hline \multirow{2}{*}{ Education } & PRE knowledge about bank and its purpose & 8.700 & 5 & 1.740 & 2.265 & .056 \\
\hline & POST knowledge about bank and its purpose & 9.508 & 5 & 1.902 & 16.147 & .000 \\
\hline \multirow{2}{*}{ Age } & PRE knowledge about bank and its purpose & 2.528 & 6 & .421 & .548 & .770 \\
\hline & POST knowledge about bank and its purpose & .298 & 6 & .050 & .422 & .862 \\
\hline Education * Age & PRE knowledge about bank and its purpose & 8.114 & 15 & .541 & .704 & .773 \\
\hline
\end{tabular}


Effect of Public Distribution System Workers in Influencing the Women Street Vendors to Use Banks...

Table 6: Post hoc Test - Tuckey's HSD

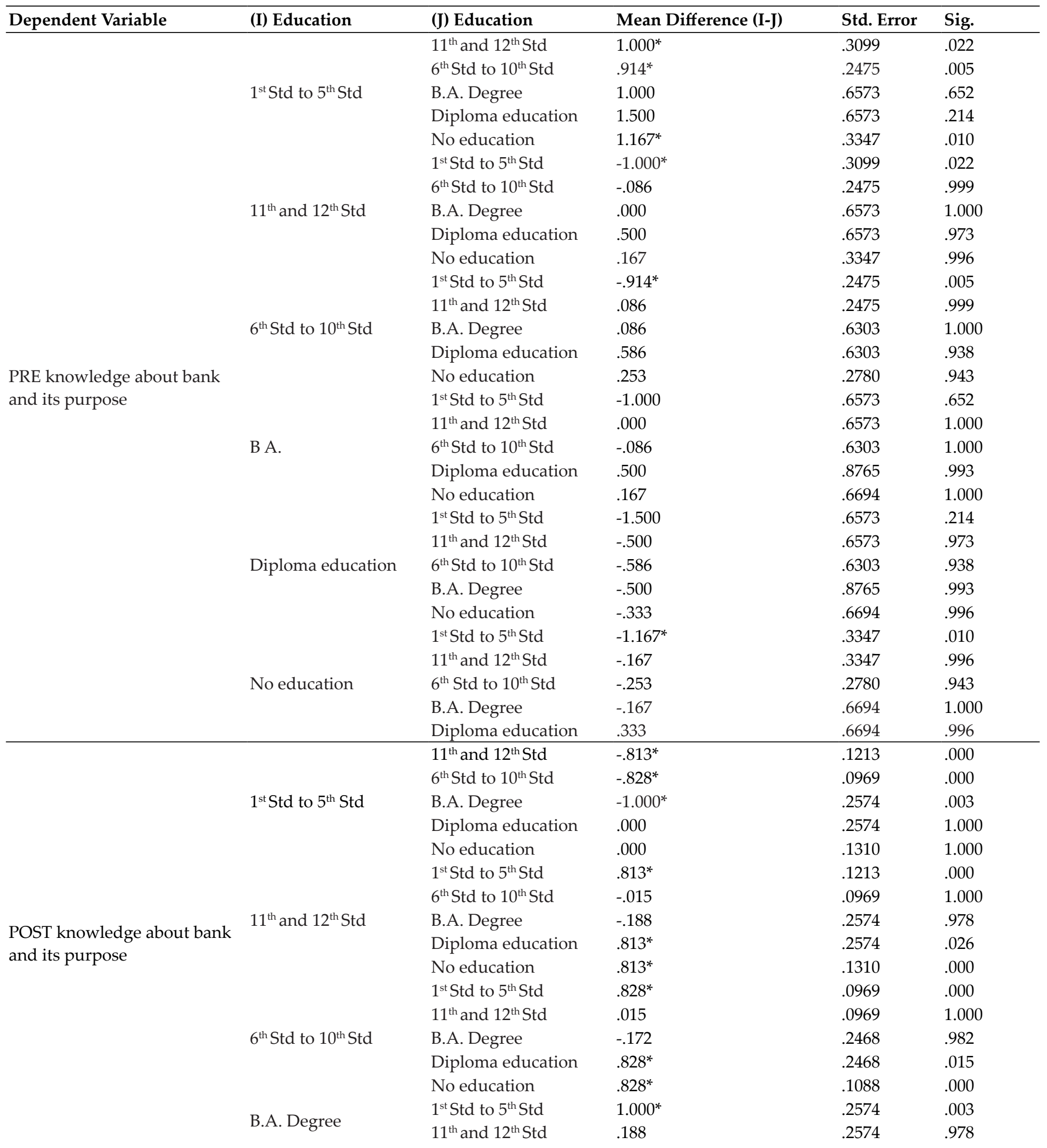




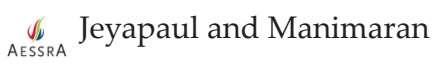

\begin{tabular}{lllll} 
& $6^{\text {th }}$ Std to $10^{\text {th }}$ Std & .172 & .2468 & .982 \\
& Diploma education & 1.000 & .3432 & .051 \\
& No education & $1.000^{*}$ & .2621 & .004 \\
& $1^{\text {st }}$ Std to $5^{\text {th }}$ Std & .000 & .2574 & 1.000 \\
& $11^{\text {th }}$ and $12^{\text {th }}$ Std & $-.813^{*}$ & .2574 & .026 \\
Diploma education & $6^{\text {th }}$ Std to $10^{\text {th }}$ Std & $-.828^{*}$ & .2468 & .015 \\
& B.A. Degree & -1.000 & .3432 & .051 \\
& No education & .000 & .2621 & 1.000 \\
& $1^{\text {st }}$ Std to $5^{\text {th }}$ Std & .000 & .1310 & 1.000 \\
No education & $12^{\text {th }}$ Std & $-.813^{*}$ & .1310 & .000 \\
& $6^{\text {th }}$ Std to $10^{\text {th }}$ Std & $-.828^{*}$ & .1088 & .000 \\
& B.A. Degree & $-1.000^{*}$ & .2621 & .004 \\
& Diploma education & .000 & .2621 & 1.000 \\
\hline
\end{tabular}

* The mean difference is significant at the .05 level.

of PDS workers counseling on banks, but women SVs education has a significant impact on how they accept PDS workers counseling on banks.

The various education levels of women SVs are as follows: No education, $1^{\text {st }}$ Std to $5^{\text {th }}$ Std, $6^{\text {th }}$ Std to $10^{\text {th }}$ Std, $11^{\text {th }}$ and $12^{\text {th }}$ Std, Diploma education, and B.A. Degree. In order to find out exactly what education level influences the acceptance of PDS workers counseling among women SVs, a post hoc test is carried out. Since age has no significant impact, only the education status of the women SVs are considered for the post - hoc test, and age is not considered further. The post hoc test carried out is 'Tuckey's honestly significant difference (HSD).

Considering the $\mathrm{p}$ values (at $\mathrm{p} \leq .05$ ) in Table 6, it is observed that under PRE knowledge about bank and its purpose comparing the $1^{\text {st }}$ Std to $5^{\text {th }}$ Std with other education levels, the impact of "'education' in PRE is influenced by $1^{\text {th }}$ and $12^{\text {th }} \mathrm{Std}, 6^{\text {th }} \mathrm{Std}$ to $10^{\text {th }} \mathrm{Std}$ and women SVs with No education. However, the interrelationship with other education levels is not significant. Thus, it is concluded that those women SVs with higher education levels had better knowledge about the operation of the banks and its purpose than the lower educated Women SVs. Considering the p-value in the POST section, it is found that the impact of PDS workers is higher with the Women SVs whose education levels are lower. However, there is no improvement on the opinion in the women SVs whose education level is higher because they had sufficient knowledge about the banks already.

\section{CONCLUSION}

The research was done to find out the impact of PDS workers to advise and educate the women SVs to use banks as their primary source of the financial service provider. The study was conducted in two phases. In Phase I, the PDS workers in the locality of the Women SVs were used to educate them on the importance of using banks to save money and the benefits they get in due course like getting loans an affordable interest rate, etc., After six months, the same Women SVs were met (Phase II) and the level of SVs who started to use banks as their primary financial source was analyzed. It was found that there was a significant improvement in the knowledge the SVs have towards the bank and its purpose in Phase II of the study after the PDS workers counseled them. The Education level has a significant impact due to the counseling of the PDS workers, and Age of the SVs has no impact due to it. The policymakers can use the PDS workers, who are already familiar within the locality and have a greater impact in influencing the Women SVs to use banks as their main financial service. This will make SVs to come inside the formal sector and will contribute better for the growth of the economy as a whole.

\section{ACKNOWLEDGEMENTS}

This article is a part of the Indian Council of Social Science Research - Impactful Policy Research in Social Science (ICSSR - IMPRESS) sponsored project received 
by the authors of this article for the duration (April 2019 - March 2021) under the topic "A strategic model creation for sustainable financial inclusion through influencers for under-privileged sections of the society" under grant number IMPRESS/P604/58/2018-19/ICSSR.

\section{REFERENCES}

Abebe, Y.M. 2017. February. Challenges and opportunities of women participating in informal sector in Ethiopia: A special focus on women street vendors in Arba Minch City. Int. J. Socio. Anthropol., 9(2): 8-16.

Begari, P. 2017. July. Education Level of Street Vendors and Its Impact on Performance of the Activity: A Case Study of Hyderabad, Telangana. Int. J. Res. Econ. Soc. Sci., 7(7): 436-443.

Bernal-Torres, C.A., Peralta-Gómez, M.C. and Thoene, U. 2020. February. Street vendors in Bogotá, Colombia, and their meanings of informal work. Cogent Psy., 7(1).

Chakraborty, S. 2018. December. Life of Women Street Vendors: Protection of Livelihood and Need For Regulation. (A. Batra, Ed.) Business World.

Cohen, M., Bhatt, M. and Horn, P. 2000. Women Street Vendors: The Road to Recognition. SEEDS, Population Council, New York.

El-Azzazy, M.A. 2019. Street Vending Challenges and opportunities: The case of the women fish vendors in Fayoum. $\mathrm{PhD}$ Thesis, The American University in Cairo - School of Global Affairs and Public Policy, The Public Policy and Administration Department, Cairo.

Ghosh, S. and Vinod, D. 2017. April. What Constrains Financial Inclusion for Women? Evidence from Indian Micro data. World Dev., 92: 60-81.

Gupta, A. 2021. Financial Inclusion and Female Labour Force Participation. The Initiative for What Works to Advance Women and Girls in the Economy and Institute of Social Studies Trust, New Delhi.

Ismail, A. and Umar, F. 2018. October. Female Street Vendors in Domestic and Public Violence. Adv. Soc. Sci. Edu. Hum. Res., 226.

Kaur, G., Ramachandran, R. and Nanda, R.B. 2020. Impact of Covid 19 National Lockdown on Women Street Vendors in Delhi. Institute of Social Studies Trust, New Delhi.

Kaur, S. 2020. What does Covid 19 mean for the livelihood of women street vendors? Breakthrough, New Delhi.

Lemessa, S.D., Watabaji, M.D., Yismaw, M.A. and Tadesse, A.B. 2021. Evening street vending and the tragic living conditions of vendors: The case of eastern Ethiopia region. Cities, 108.
Mungai, A.W., Kihonge, E. and Gichure, J. 2019. Effect of Proactiveness on the Growth of Women Street Vending in Kenya. J. Entrep. Proj. Manag., 3(2): 35-63.

PMJDY. 2014, August. Retrieved from Pradhan Mantri Jan-Dhan Yojana: https://pmjdy.gov.in/about

Sarker, M.I., Rahman, M., Cao, Q. and Xu, Z. 2019. Impact of small entrepreneurship on poverty alleviation and sustainable livelihood of street vendors. Int. J. Innov. App. Stu., 25(4): 12411254.

Sekhani, R., Mohan, D. and Medipally, S. 2019. Street vending in urban "'informal' markets: Reflections from case-studies of street vendors in Delhi (India) and Phnom Penh City (Cambodia). Cities, 89: 120-129.

Sen, R.K. and Gupta, S. 2017. September. Struggle for Social Space, From Residence to Road: A Special Focus on Women Street Vendors of Barasat and Basirhat Municipal Area, North Twenty Four Parganas District, West Bengal. IOSR J. Hum. Soc. Sci., 22(9): 63-71.

Singh, K. and Gupta, N. 2020. Financial Inclusion in India-A Review. Indian J. Eco. Dev., 16(2): 278-284.

Swamy, R. and Singh, A. 2018. Creating a Supportive Entrepreneurial Ecosystem for Street Vendors: The Case of the National Association of Street Vendors of India (NASVI). In: A.H. Leitão J. (Ed.), Applying Quality of Life Research (pp. 151-172). Springer.

Thabani, N. 2017. December. An empirical investigation of factors affecting the performance of women entrepreneurs in Harare: A case of food vendors. Munich Personal RePEc Archiv.

Thakur, S.S., Narula, M., Rathi, A., Midha, N., Sharma, N., Rehman, S.F. et al. 2017. A Socio-Economic Analysis of Women Street Vendors in Delhi: Questioning the Efficacy of An Exclusive Ladies Market. DU. J. Undergrad Res. Innov., 3(2): 1229.

The Economic Times. 2020. Retrieved from Definition of 'Public Distribution System': https://economictimes.indiatimes.com/ definition/Public-distribution-system Last Accessed on $24^{\text {th }}$ December 2020.

Targeted Public Distribution System (TPDS). 1997. Retrieved from Targeted Public Distribution System (TPDS): https://dfpd.gov. in/pds-tpds.htm Last Accessed on 14 ${ }^{\text {th }}$ January, 2021.

Truong, V.D. 2018. Tourism, poverty alleviation, and the informal economy: The street vendors of Hanoi, Vietnam. Tourism Recreation Res., 43(1): 52-67. 
